Article

\title{
Frequency, Spectrum, and Stability of Leaf Mutants Induced by Diverse $\gamma$-Ray Treatments in Two Cymbidium Hybrids
}

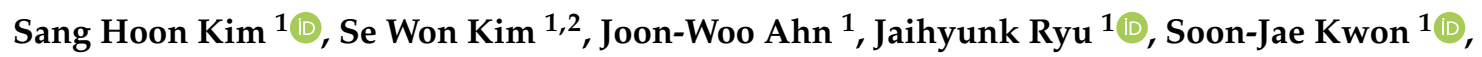 \\ Byoung-Cheorl Kang ${ }^{3}$ and Jin-Baek Kim ${ }^{1, *(\mathbb{D}}$ \\ 1 Advanced Radiation Technology Institute, Korea Atomic Energy Research Institute, Jeongeup 56212, Korea; \\ shkim80@kaeri.re.kr (S.H.K.); sewonk@korea.kr (S.W.K.); joon@kaeri.re.kr (J.-W.A.); jhryu@kaeri.re.kr (J.R.); \\ soonjaekwon@kaeri.re.kr (S.-J.K.) \\ 2 National Institute of Agricultural Sciences, Rural Development Administration, Jeonju 54874, Korea \\ 3 Department of Plant Science, Plant Genomics and Breeding Institute, and Vegetable Breeding Research \\ Center, College of Agriculture and Life Sciences, Seoul National University, Seoul 08826, Korea; \\ bk54@snu.ac.kr \\ * Correspondence: jbkim74@kaeri.re.kr; Tel.: +82-63-570-3313; Fax: +82-63-570-3811
}

Received: 20 March 2020; Accepted: 21 April 2020; Published: 23 April 2020

\begin{abstract}
Ionizing radiation combined with in vitro tissue culture has been used for development of new cultivars in diverse crops. The effects of ionizing radiation on mutation induction have been analyzed on several orchid species, including Cymbidium. Limited information is available on the comparison of mutation frequency and spectrum based on phenotypes in Cymbidium species. In addition, the stability of induced chimera mutants in Cymbidium is unknown. In this study, we analyzed the radiation sensitivity, mutation frequency, and spectrum of mutants induced by diverse $\gamma$-ray treatments, and analyzed the stability of induced chimera mutants in the Cymbidium hybrid cultivars RB003 and RB012. The optimal $\gamma$-irradiation conditions of each cultivar differed as follows: RB003, mutation frequency of 4.06\% (under $35 \mathrm{~Gy} / 4 \mathrm{~h}$ ); RB012, 1.51\% (20 Gy/1 h). Re-irradiation of $\gamma$-rays broadened the mutation spectrum observed in RB012. The stability of leaf-color chimera mutants was higher than that of leaf-shape chimeras, and stability was dependent on the chimera type and location of a mutation in the cell layers of the shoot apical meristem. These results indicated that short-term $\gamma$-irradiation was more effective to induce mutations in Cymbidium. Information on the stability of chimera mutants will be useful for mutation breeding of diverse ornamental plants.
\end{abstract}

Keywords: $\gamma$-ray; mutation; frequency; spectrum; chimera; stability; Cymbidium

\section{Introduction}

The Orchidaceae is among the largest families of angiosperms, and is composed of approximately 736 genera and about 28,000 species [1]. Among the diverse genera in the family, Dendrobium, Phalaenopsis, Oncidium, and Cymbidium are important floricultural crops in Asian countries [2]. In particular, Cymbidium is economically important in northeastern Asia, including Korea, China, and Japan [3]. Cymbidium species are conveniently divided into two groups on the basis of the native habitat and climate region, i.e., temperate and subtropical or tropical regions [4,5]. There is continuous demand for development of new Cymbidium cultivars on account of the attractiveness of the foliage as well as the flower colors and fragrance. To date, many Cymbidium cultivars have been developed via natural selection or artificial cross-breeding, although transformation has also been applied in Cymbidium 
breeding [6]. However, development of a new Cymbidium cultivar by means of cross-breeding is time-consuming because of the long vegetative growth stage.

Mutation breeding techniques using physical mutagens (e.g., $\gamma$-rays, $\mathrm{X}$-rays, and ion particles) or chemical mutagens (e.g., ethyl methanesulfonate, $N$-nitroso- $N$-methylurea, and colchicine) have been widely used to develop mutant cultivars in diverse plant species, including food and ornamental crops. In 226 plant species, 3308 mutants, including two Cymbidium mutants, that were predominantly $(77.5 \%)$ developed using physical mutagens have been registered in the Mutant Variety Database of the joint Food and Agriculture Organization of the United Nations/International Atomic Energy Agency [7]. Among the diverse ornamental plants registered on the database, the most numerous mutants are those of chrysanthemum (Chrysanthemum spp., 274 mutants) followed by rose (Rosa spp., 67 mutants), dahlia (Dahlia spp., 36 mutants), alstroemeria (Alstroemeria spp., 35 mutants), streptocarpus (Streptocarpus spp., 30 mutants), and carnation (Dianthus caryophyllus, 28 mutants) [7]. The combination of treatment with a physical mutagen and in vitro tissue culture has been used to shorten the breeding period of orchids $[8,9]$. Thus, integration of $\gamma$-irradiation and in vitro tissue culture may be an efficient procedure for development of mutant cultivars in Cymbidium.

The treatment of seeds, buds (tip/node cuttings), callus, and rhizomes with a mutagen induces chimeras in $\mathrm{M}_{1}$ plants because mutations are induced in individual cells and regenerated shoots are recovered from pre-existing multicellular meristems [10]. In seed-propagated plants, the induced chimera is commonly dissociated by selfing of $\mathrm{M}_{1}$ plants, whereas, in vegetatively propagated plants chimera dissociation by selfing is of limited use because selfing results in loss of the desirable original characteristics. Geier [10] suggests that plant regeneration via adventitious buds or somatic embryos, which permits the genetic background to be retained, may be useful to dissociate the chimera in vegetatively propagated plants. In the majority of angiosperms, the shoot apical meristem (SAM) is composed of three layers: the outer meristem layer (L1), the second meristem layer (L2), and the inner corpus (L3) [11,12]. Mutagen-treated plants are composed of heterogeneous cells in the three layers, which can be categorized into three chimera types: sectorial chimeras, which have an unstable heterogenomic population of cells traversing more than one layer of the SAM; mericlinal chimeras, which have an unstable heterogenomic population of cells within a single layer of the SAM; and periclinal chimeras, which have a stable, uniform, and genetically distinguished layer of cells of the SAM [10,12]. The phenotypes of mutants are diverse according to the type and extent of these chimeras. Thus, an understanding of chimerism is necessary to develop a new Cymbidium mutant cultivar by mutagenesis.

In the present study, we evaluated the optimal $\gamma$-ray dose to induce mutations in Cymbidium, and compared the mutation frequency and spectrum of leaf mutants induced by diverse $\gamma$-ray treatments. In addition, we investigated the stability of chimera mutants using plants secondarily regenerated from selected rhizomes and the initially regenerated mutant plant.

\section{Results}

\subsection{Effects of $\gamma$-Irradiation on Rhizome Growth Parameters}

At 3 months after $\gamma$-irradiation, the relative weight of the $\gamma$-irradiated rhizomes of the cultivars RB003 and RB012 gradually decreased with increase in $\gamma$-ray dose. At 6 months after $\gamma$-irradiation, the responses of rhizomes to $\gamma$-irradiation were more distinct; rhizome growth was strongly inhibited at $\gamma$-ray doses of more than 60 and $40 \mathrm{~Gy}$ in RB003 and RB012, respectively (Figure 1a). All $\gamma$-irradiated rhizomes of the two cultivars survived at 3 and 6 months after irradiation (Figure 1b). However, at 3 months after $\gamma$-irradiation the multiplication rate of the $\gamma$-irradiated rhizomes rapidly decreased at doses of more than 60 and 40 Gy in RB003 and RB012, respectively. In addition, at 6 months after $\gamma$-irradiation, multiplication was not observed at doses of more than $80 \mathrm{~Gy}$ in the two cultivars (Figure 1c). The $\gamma$-irradiated rhizomes were regenerated from about 8 months after irradiation in the two cultivars, although regeneration of the control was detected from 7 months after initial culture. 
Therefore, the relative regeneration rate of $\gamma$-irradiated populations was evaluated at 9 months after irradiation. The regeneration of RB003 rhizomes decreased in a dose-dependent manner and strongly inhibited regeneration was observed at doses of more than 60 Gy. However, RB012 rhizomes irradiated with 20 Gy showed a higher rate of regeneration compared with that of the control, and at doses exceeding 40 Gy regeneration was strongly suppressed (Figure 1d).

(a)

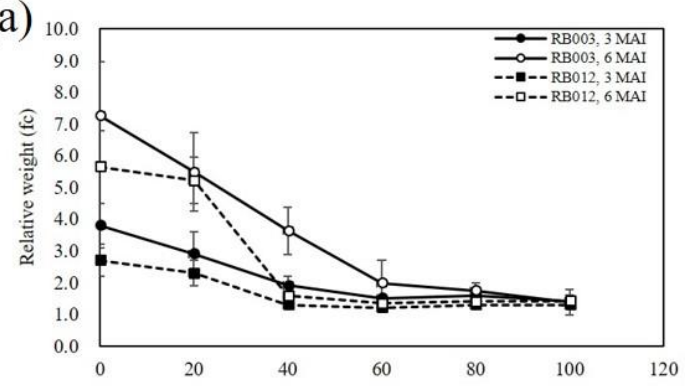

(c)

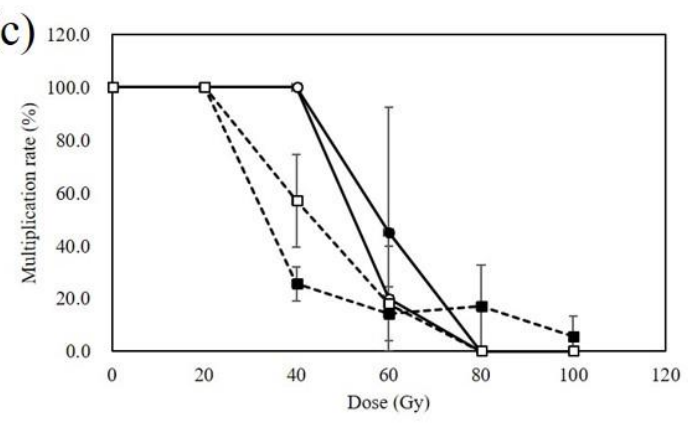

(b)

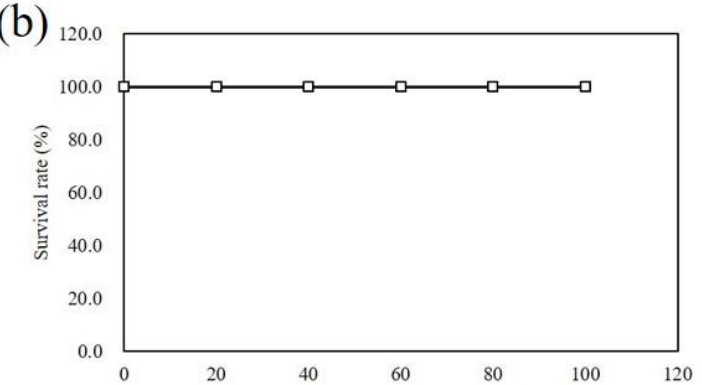

(d) 1

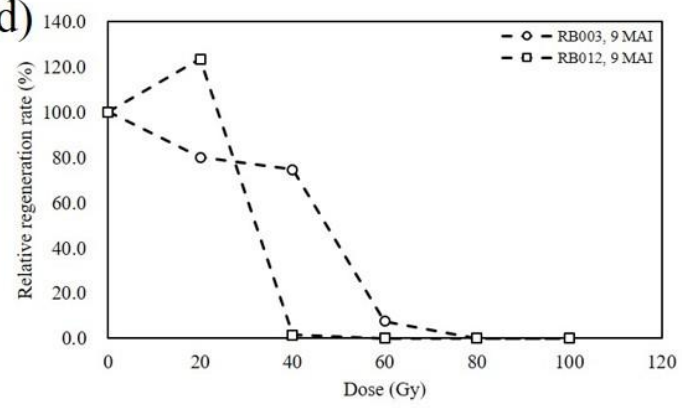

Figure 1. Relative weight, survival, multiplication, and relative regeneration rate of Cymbidium hybrids, RB003 and RB012 rhizomes at 3, 6, and 9 months after $\gamma$-irradiation. (a) Relative weight of rhizomes; (b) survival rate of rhizomes; (c) multiplication rate of rhizomes; (d) relative regeneration rate of rhizomes. Relative weight, survival, and multiplication rate of rhizomes were measured at 3 and 6 months after irradiation, whereas the relative regeneration rate was analyzed at 9 months. fc, fold-change. MAI, months after irradiation. Error bars indicate the standard error of the mean $(n=5)$.

Given that all $\gamma$-irradiated populations survived during the first 6 months after treatment, it was impossible to estimate the $50 \%$ lethal dose $\left(\mathrm{LD}_{50}\right)$ for the two cultivars (Figure $1 \mathrm{~b}$ ). At 3 months after $\gamma$-irradiation of rhizomes, the $50 \%$ reduction dose $\left(\mathrm{RD}_{50}\right)$ for the two cultivars was estimated as follows: RB003, 30.0 Gy (based on the relative weight) and 58.2 Gy (based on the multiplication rate); and RB012, 29.0 Gy (based on the relative weight) and 33.5 Gy (based on the multiplication rate). At 6 months, the estimated $\mathrm{RD}_{50}$ for each cultivar was as follows: RB003, 34.4 Gy (based on the relative weight) and 52.5 Gy (based on the multiplication rate); and RB012, 30.6 Gy (based on the relative weight) and $44.1 \mathrm{~Gy}$ (based on the multiplication rate) (Figure $1 \mathrm{a}, \mathrm{c}$ ). At 9 months, the $\mathrm{RD}_{50}$ based on the relative regeneration rates for each cultivar was 47.4 Gy and 34.4 Gy for RB003 and RB012, respectively (Figure 1d).

\subsection{Comparison of Mutation Frequency and Spectrum among $\gamma$-Irradiated Populations}

In the RB003 populations, the mutation frequency was elevated with an increase in $\gamma$-ray dose rate as follows: $50 \mathrm{~Gy} / 24 \mathrm{~h}$, mutation frequency of $0.35 \%$; $50 \mathrm{~Gy} / 16 \mathrm{~h}, 0.81 \%$; and $50 \mathrm{~Gy} / 8 \mathrm{~h}, 3.73 \%$. In addition, the two populations $\gamma$-irradiated with $50 \mathrm{~Gy} / 8 \mathrm{~h}$ and $35 \mathrm{~Gy} / 4 \mathrm{~h}$ showed the same mean regenerants per bottle of 3.11 as well as similar mutation frequencies: $50 \mathrm{~Gy} / 8 \mathrm{~h}$, mutation frequency of $3.73 \%$; and $35 \mathrm{~Gy} / 4 \mathrm{~h}, 4.06 \%$. Under these irradiation conditions, the mutation frequency and spectrum were the highest observed among the $\gamma$-irradiated RB003 populations (Table 1). 
Table 1. Regeneration, mutation frequency, and spectrum of leaf mutants derived from diverse $\gamma$-ray treatments in the Cymbidium hybrids RB003 and RB012.

\begin{tabular}{|c|c|c|c|c|c|}
\hline $\begin{array}{l}\text { Total Dose/Irradiation } \\
\text { Duration }\end{array}$ & $\begin{array}{l}\text { No. of Regenerants per } \\
\text { Cultured Bottle }\end{array}$ & $\begin{array}{l}\text { No. of Mutants } \\
(\%)\end{array}$ & $\begin{array}{l}\text { Description of Mutants (No. of Mutants) } \\
\text { Leaf Color }\end{array}$ & Leaf Shape & $\begin{array}{l}\text { Mutation } \\
\text { Spectrum }\end{array}$ \\
\hline \multicolumn{6}{|l|}{ RB003 } \\
\hline Control & $5.42 \mathrm{a}^{\mathrm{a}}$ & $0\left(0.00 \mathrm{a}^{\mathrm{b}}\right)$ & - & - & - \\
\hline $50 \mathrm{~Gy} / 24 \mathrm{~h}$ & $2.50 \mathrm{~b}$ & $1(0.35 \mathrm{a})$ & Comb/yellow broad stripe (1) & - & 1 \\
\hline $50 \mathrm{~Gy} / 16 \mathrm{~h}$ & 3.04ab & $3(0.81 a)^{c}$ & Comb (1), bright green/yellow large spot (1), yellow marginal stripe (1) & Wrinkle (1) & 4 \\
\hline $50 \mathrm{~Gy} / 8 \mathrm{~h}$ & $3.11 \mathrm{ab}$ & $11(3.73 b)$ & $\begin{array}{l}\text { Bright green/yellow large spot (1), bright green (2), comb (3), comb/yellow } \\
\text { broad stripe (1), bright green/comb (1), }\end{array}$ & $\begin{array}{l}\text { Abnormal (2), dwarf (1), } \\
\text { wrinkle (4) }\end{array}$ & 8 \\
\hline $35 \mathrm{~Gy} / 4 \mathrm{~h}$ & $3.11 \mathrm{ab}$ & $14(4.06 b)$ & $\begin{array}{l}\text { Yellow marginal stripe (1), bright green (2), comb/yellow broad stripe (1), } \\
\text { yellow marginal/narrow stripe (1), bright green/yellow large spot (3) }\end{array}$ & Wrinkle (5), dwarf (1) & 7 \\
\hline $25 \mathrm{~Gy} / 1 \mathrm{~h}$ & $3.42 \mathrm{ab}$ & 7 (2.02ab) & $\begin{array}{c}\text { Bright green/comb (2), bright green/yellow large spot (2), yellow marginal } \\
\text { stripe (1) }\end{array}$ & Abnormal (2) & 4 \\
\hline \multicolumn{6}{|c|}{ 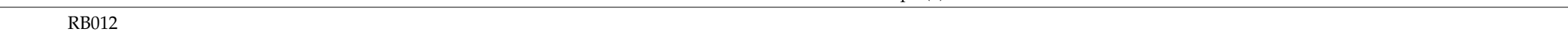 } \\
\hline Control & $16.67 \mathrm{a}$ & $0(0.00 \mathrm{a})$ & & - & - \\
\hline $40 \mathrm{~Gy} / 24 \mathrm{~h}$ & $4.63 \mathrm{bc}$ & $9(1.42 b)$ & $\begin{array}{l}\text { Yellow narrow stripe (1), yellow large spot (4), snakeskin (2), yellow } \\
\text { marginal stripe (2), }\end{array}$ & - & 4 \\
\hline $40 \mathrm{~Gy} / 16 \mathrm{~h}$ & $1.82 \mathrm{~cd}$ & $1(0.23 \mathrm{a})$ & Yellow marginal stripe (1) & - & 1 \\
\hline $40 \mathrm{~Gy} / 8 \mathrm{~h}$ & $0.11 \mathrm{~d}$ & $0(0.00 \mathrm{a})$ & - & - & - \\
\hline $30 \mathrm{~Gy} / 4 \mathrm{~h}$ & $0.65 \mathrm{~d}$ & $3(3.24 \mathrm{c})$ & Yellow marginal stripe (2), yellow large spot (1) & - & 2 \\
\hline $20 \mathrm{~Gy} / 1 \mathrm{~h}$ & $4.36 \mathrm{bc}$ & $10(1.51 b)$ & $\begin{array}{l}\text { Yellow marginal stripe (2), yellow large spot (3), bright green (1), } \\
\text { snakeskin (2), yellow narrow stripe (1), yellow broad stripe (1) }\end{array}$ & - & 6 \\
\hline $30 \mathrm{~Gy} / 24 \mathrm{~h}$ & $7.14 \mathrm{~b}$ & $4(0.68 \mathrm{a})$ & Yellow large spot (1), yellow marginal stripe (2) & Abnormal (1) & 3 \\
\hline 30-30 Gy/24 h & $4.11 \mathrm{c}$ & $21(0.67 a)$ & $\begin{array}{l}\text { Yellow narrow stripe (1), yellow marginal stripe (6), yellow broad stripe } \\
\text { (3), bright green (1), yellow large spot (5), snakeskin (1), }\end{array}$ & $\begin{array}{l}\text { Wrinkle (1), dwarf (1), } \\
\text { abnormal (2) }\end{array}$ & 9 \\
\hline
\end{tabular}

a, b Values are means $(n=3)$. Mean values followed by different lower-case letters within each column for each treatment were significantly different at $p \leq 0.05$ using Duncan's multiple range test; ${ }^{c}$ A mutant showing more than two characteristics was counted as only one. 
In the RB012 populations, the mean regenerants per bottle decreased precipitously with increase in $\gamma$-ray dose rate as follows: $40 \mathrm{~Gy} / 24 \mathrm{~h}$, mean regenerants per bottle of $4.63 ; 40 \mathrm{~Gy} / 16 \mathrm{~h}, 1.82$; and $40 \mathrm{~Gy} / 8 \mathrm{~h}, 0.11$. The two populations $\gamma$-irradiated with $40 \mathrm{~Gy} / 24 \mathrm{~h}$ and $20 \mathrm{~Gy} / 1 \mathrm{~h}$ showed similar mean regenerants per bottle (4.63 and 4.36, respectively) as well as similar mutation frequencies: $40 \mathrm{~Gy} / 24 \mathrm{~h}$, mutation frequency of $1.42 \%$; and $20 \mathrm{~Gy} / 1 \mathrm{~h}, 1.51 \%$. The highest mutation frequency observed was $3.24 \%$ in the irradiation condition $30 \mathrm{~Gy} / 4 \mathrm{~h}$; however, it is impossible to consider this is to be the optimal irradiation condition because of the severely reduced regeneration. The highest mutation spectrum was observed in the population $\gamma$-irradiated with $20 \mathrm{~Gy} / 1 \mathrm{~h}$, which also showed the second-highest mutation frequency of $1.51 \%$ (Table 1). In the re-irradiated RB012 population, regeneration was reduced by $42.4 \%$ after re-irradiation (30-30 Gy/24 h) of the RB012 population initially $\gamma$-irradiated with $30 \mathrm{~Gy} / 24 \mathrm{~h}$ (Table 1). Compared with the RB012 population $\gamma$-irradiated with $30 \mathrm{~Gy} / 24$ $\mathrm{h}$, the mutation spectrum of the re-irradiation (30-30 Gy/24 h) population was broader, although no difference in mutation frequency was observed (Table 1).

In the $\gamma$-irradiated populations of the two cultivars, diverse leaf-color or -shape mutants were observed and the proportion of leaf-color mutants was higher than that of leaf-shape mutants (Table 1 , Figure 2).

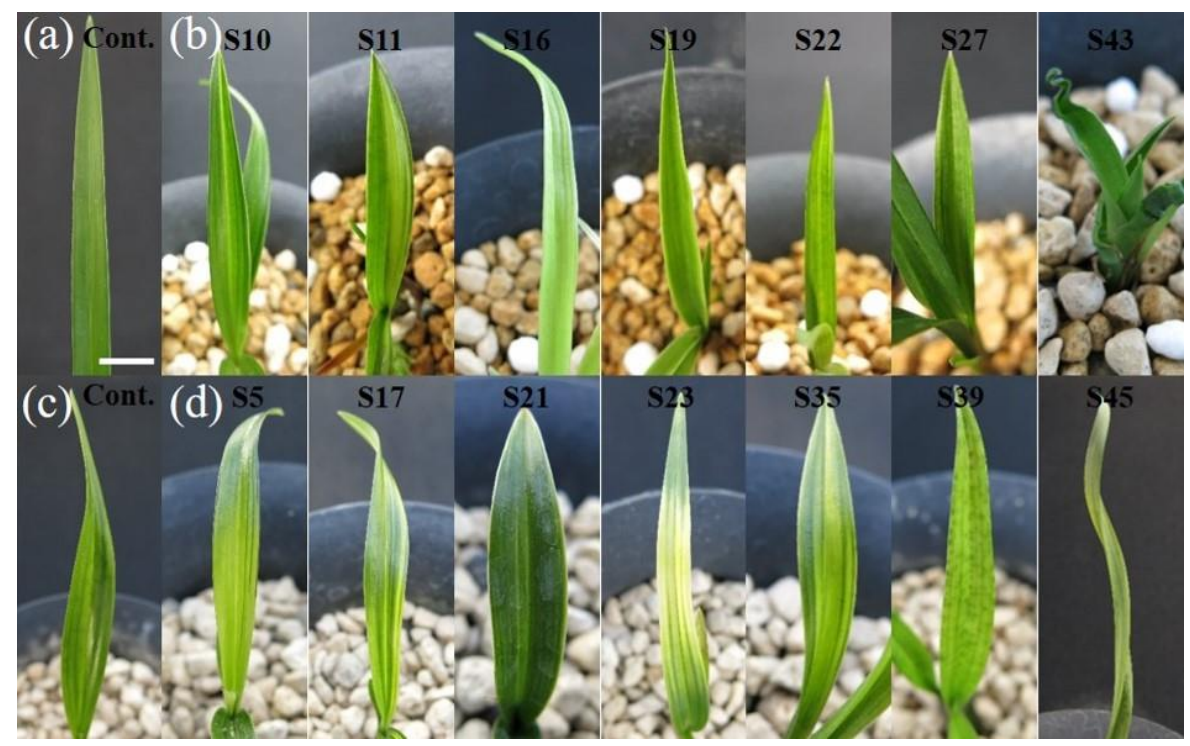

Figure 2. Diverse leaf-color or -shape mutants derived from Cymbidium hybrids RB003 and RB012. (a) RB003 control; (b) leaf mutants derived from RB003; (c) RB012 control; (d) leaf mutants derived from RB012. (b) indicates S10, S11, S16, S19, S22, S27 (leaf-color mutants), and S43 (leaf-shape mutant), while (d) indicates S5, S17, S21, S23, S35, S39 (leaf-color mutants), and S45 (leaf-shape mutant). Scale bar: $1 \mathrm{~cm}$.

\subsection{Evaluation of Stability among Leaf Mutants}

A total of 101 leaf-color or -shape mutants (52 mutants derived from RB003 and 49 from RB012) were tested to analyze the stability of the induced chimera mutants (Table 2). The chimera stability of the first selected mutant plant induced by regeneration of $\gamma$-irradiated rhizomes was higher than that of the rhizome closely attached to the mutant plant: RB003, plant (43.4\%), rhizome (33.3\%); and RB012, plant (33.3\%), rhizome (18.6\%). The leaf-color mutants were observed to be relatively stable chimera types, but the leaf-shape mutants were unstable in the two cultivars. The most stable chimera type was the yellow marginal stripe types, which showed stability of $50.0 \%$ (from the rhizome) and $83.3 \%$ (from the plant) (assumed to be a periclinal chimera, a mutation of the L2 layer of the SAM), followed by: yellow broad stripe types with stability of 50.0\% (rhizome) and 66.6\% (plant) (assumed to be a periclinal chimera, a mutation of the L3 layer of the SAM); yellow narrow stripe types with stability of $25.5 \%$ (rhizome) and 100\% (plant) (assumed to be a mericlinal chimera, a mutation of the L3 
layer); bright green types with stability of $25.0 \%$ (rhizome) and $50.0 \%$ (plant) (assumed to be a sectorial chimera, a mutation of the L2 and L3 layers); yellow large spot types with stability of $12.5 \%$ (rhizome) and $12.5 \%$ (plant); and comb types with stability of $0 \%$ (rhizome) and $33.3 \%$ (plant) (assumed to be a mericlinal chimera, a mutation of the L3 layer) (Table 2). In the case of the selected mutant RB012-S17, the phenotype of the first selected mutant plant induced by regeneration of $\gamma$-irradiated rhizomes with $40 \mathrm{~Gy} / 24 \mathrm{~h}$ was of the yellow narrow stripe type; however, newly regenerated in vitro plants from the rhizome closely attached to the mutant plant segregated in the $M_{1} V_{1}$ generation, and the yellow broad stripe type ultimately selected was stabilized in the $\mathrm{M}_{1} \mathrm{~V}_{5}$ generation (Figure 3).

Table 2. Stability of leaf mutants induced by $\gamma$-irradiation in the Cymbidium hybrids, RB003 and RB012 populations.

\begin{tabular}{cccc}
\hline Characteristic & No. of Mutants & \multicolumn{2}{c}{ Stability (\%) } \\
& & Rhizome $^{\mathbf{a}}$ & Plant $^{\mathbf{b}}$ \\
\hline RB003 & & & \\
Yellow marginal stripe, color & 3 & - & $3 / 3(100.0)$ \\
Yellow broad stripe, color & 3 & - & $1 / 2(50.0)$ \\
Yellow narrow stripe, color & 1 & - & $1 / 1(100.0)$ \\
Bright green, color & 15 & $2\left(2^{\mathrm{c}}\right) / 6(33.3)$ & $3 / 6(50.0)$ \\
Yellow large spot, color & 7 & $2 / 2(100.0)$ & $1 / 2(50.0)$ \\
Comb, color & 7 & $0 / 1(0.0)$ & $1 / 3(33.3)$ \\
Dwarf, shape & 2 & - & - \\
Wrinkle, shape & 10 & $0 / 3(0.0)$ & $0 / 5(0.0)$ \\
Abnormal, shape & 4 & - & $0 / 1(0.0)$ \\
Total & 52 & $4(2) / 12(33.3)$ & $10 / 23(43.4)$ \\
RB012 & & & \\
Rellow marginal stripe, color & 14 & $5(2) / 10(50.0)$ & $2 / 3(66.7)$ \\
Yellow broad stripe, color & 4 & $2(1) / 4(50.0)$ & $1 / 1(100.0)$ \\
Yellow narrow stripe, color & 4 & $1(2) / 4(25.0)$ & $2 / 2(100.0)$ \\
Bright green, color & 2 & $0 / 2(0.0)$ & - \\
Yellow large spot, color & 15 & $0 / 14(0.0)$ & $0 / 6(0.0)$ \\
Snakeskin, color & 5 & $0 / 5(0.0)$ & - \\
Dwarf, shape & 1 & $0 / 1(0.0)$ & - \\
Wrinkle, shape & 1 & $0 / 1(0.0)$ & $0 / 1(0.0)$ \\
Abnormal, shape & 3 & $0 / 2(0.0)$ & $0 / 2(0.0)$ \\
Total & 49 & $8(5) / 43(18.6)$ & $5 / 15(33.3)$ \\
\hline
\end{tabular}

${ }^{\text {a }}$ Rhizome closely attached to the selected mutant plant; ${ }^{\mathrm{b}}$ Mutant plant regenerated from $\gamma$-irradiated rhizomes; c Segregation.

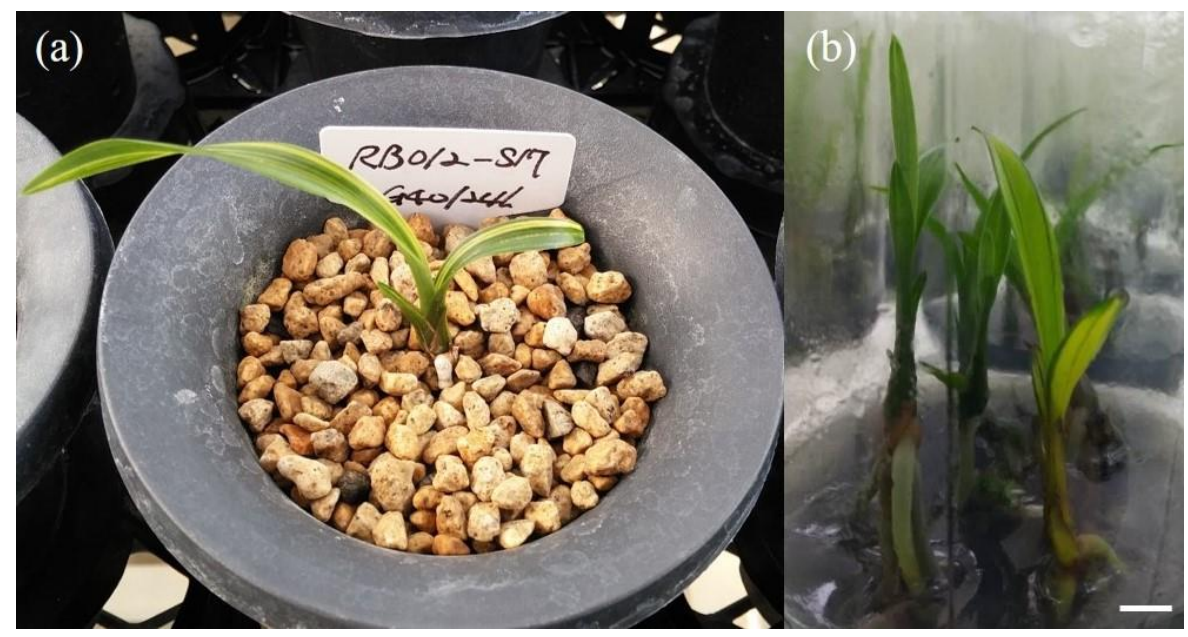

Figure 3. Segregation in the selected mutant RB012-S17. (a) The first mutant plant regenerated from $\gamma$-irradiated rhizomes; (b) segregation of newly regenerated plants from the first selected rhizomes in the $\mathrm{M}_{1} \mathrm{~V}_{1}$ generation. Scale bar: $1 \mathrm{~cm}$. 


\section{Discussion}

\subsection{Optimal $\gamma$-Irradiation Condition for Mutation Induction}

In plant mutation breeding, the optimal irradiation condition is considered to be the most important factor to induce desirable mutants with the minimum collateral DNA damage. Irradiation dose has been mainly used for determination of the optimal irradiation condition in diverse plant species, including orchids [5,8,13-18]. However, the optimal doses suggested by previous researchers are diverse: e.g., $\mathrm{LD}_{10}$ in rice seeds [18]; $\mathrm{LD}_{30-50}$ and $\mathrm{RD}_{30-50}$ in crop seeds [19]; $\mathrm{LD}_{20-30}$ in in vitro tissues [20]; and $\mathrm{RD}_{50}$ in Cymbidium protocorm-like bodies (PLBs) [9]. Furthermore, irradiation duration and dose rate, a complex concept of dose and duration, are also important factors for induction of mutations. The effect of dose rate on mutation induction has varied substantially in previous researches. A low dose rate was reported to be more effective to induce mutations than a high dose rate in barley and maize [21]. However, Mabuchi and Matsumura [22] suggested that a high dose rate could induce a higher mutation frequency than a low dose rate under an identical total dose in maize. In contrast, the mutation frequency is dependent on the total dose, not the dose rate, in chrysanthemum [23]. Recently, Kim et al. [24] proposed that a specific irradiation duration could induce a higher mutation frequency and broader spectrum of mutants in chrysanthemum. In the present study, we used the RD $\mathrm{D}_{50}$ based on the multiplication and relative regeneration rates as a guide to construct mutant populations from two Cymbidium cultivars (Figure 1).

\subsection{Frequency and Spectrum of Induced Leaf Mutants}

The frequency of somatic mutations is extremely low and differs considerably among plant species. In Arabidopsis, the frequency of somatic mutations was calculated as approximately $1.6 \times$ $10^{-10}$ mutations per base per cell division [25]. Somaclonal variants were observed at frequencies of $0.6 \%$ and $0.05 \%$ from tissue culture of Pelargonium spp. and a Cymbidium hybrid, respectively $[4,26]$. Luan et al. [8] analyzed the $\mathrm{LD}_{50}$, mutation frequency, and spectrum of mutants induced by $\gamma$-ray and $320 \mathrm{MeV}{ }^{12} \mathrm{C}^{6+}$ ion irradiations in two Paphiopedilum species. Several leaf-color (white margin and chlorophyll variegation) or -shape (large leaves, narrow leaves, and enormous shoot buds) mutants were observed with a mutation frequency of $3 \%$ in the two populations irradiated with $320 \mathrm{MeV}$ ${ }^{12} \mathrm{C}^{6+}$ ions of $3 \mathrm{~Gy}$, whereas no mutants were observed in the $\gamma$-irradiated populations. In addition, the proportions of leaf-color to leaf-shape mutants were 12:1 and 1:11 in the P. delenatii and P. callosum populations, respectively [8]. In two Dendrobium species, a chlorophyll variegated mutant (induced by irradiation with $0.4 \mathrm{~Gy}$ ) and leaf-shape mutants (irradiation with 0.2-2.0 Gy) were identified in the ${ }^{12} \mathrm{C}^{6+}$ ion-irradiated D. mirbellianum and D. crumenatum populations, respectively [13]. Ahmad et al. [14] reported only leaf-shape mutants (narrow and pointed leaves, and abnormally shaped leaves) in an Oncidium lanceanum population irradiated with $220 \mathrm{MeV}^{12} \mathrm{C}^{5+}$ ion of $1-2 \mathrm{~Gy}$. However, compared with previous studies, we identified a relatively higher proportion of leaf-color mutants and a broader spectrum of mutants in the present study (Table 1, Figure 2). This finding may be due to the differences in plant species or radiation type used. Furthermore, Prina et al. [27] reported that treatment of homozygous barley seeds with mutagens resulted in two types of chlorophyll variegations (light green, 70\%; and albino), whereas treatment of heterozygous seeds with mutagens dramatically changed the spectrum of somatic-sector mutations. In this respect, the high heterozygosity of the two Cymbidium cultivars, which are hybrids of C. sinense and C. goeringii, used in the current study also may be a cause of the broad mutation spectrum.

\subsection{Effects of Short-Term Irradiation and Re-irradiation on Mutation Induction}

Kim et al. [24] reported that at an identical total $\gamma$-ray dose of $30 \mathrm{~Gy}$, an irradiation duration of $4 \mathrm{~h}$ among durations of $1,4,8,16$, and $24 \mathrm{~h}$ induced the highest frequency of flower-color mutations in chrysanthemum. Kodym et al. [19] suggested that radiation-induced DNA damage is restored by a repair mechanism mainly in the $S$ phase of the DNA replication cycle and that a long duration of 
irradiation reduces the effects of the radiation dose. In the present study, the mutation frequency increased with decrease in irradiation duration in the 50 Gy-irradiated RB003 populations and the mutation frequency of the RB012 population irradiated with $20 \mathrm{~Gy} / 1 \mathrm{~h}$ was similar to that of the population $\gamma$-irradiated with $40 \mathrm{~Gy} / 24 \mathrm{~h}$. In addition, the highest mutation frequency was observed with irradiation durations of $4 \mathrm{~h}$ and $1 \mathrm{~h}$ in the RB003 and RB012 populations, respectively (Table 1). These results indicate that short-term irradiation is more effective to induce mutations than long-term irradiation in Cymbidium. Kodym et al. [19] reported that recurrent irradiation treatment was conducted to broaden the mutation spectrum and to increase the chances of obtaining desirable mutants in diverse plant species, but the experiments did not yield the expected results. However, several studies have reported the effectiveness of re-irradiation of ion particles in ornamental flower species [28]: e.g., cyclamen [29], Osteospermum spp. [30], and chrysanthemum [31]. In the present study, the mutation spectrum was broadened by re-irradiation with $\gamma$-rays, although no increase in the mutation frequency was observed and the size of the re-irradiated population was larger than that of single-irradiated population (Table 1).

\subsection{Stability of Induced Chimera Mutants}

Mutagens such as $\gamma$-rays have been applied to increase the mutation frequency and lead to genetically heterogeneous cells, which is a chimeric condition. Chimera types are determined by the mode of spread, spatial arrangement, and competitiveness of a mutated cell among the mutated and wild-type cells in the SAM layers [10]. In vegetatively propagated plants, Geier [10] suggested several practical methods for chimera dissociation, such as mechanical wounding, application of plant hormones, lateral bud sprouting, in vitro shoot proliferation, adventitious shoot regeneration, and somatic embryogenesis. In the present study, periclinal chimera types (yellow marginal stripe (assumed to be a mutation in the L2 layer) and yellow broad stripe (L3)) were more stable than mericlinal chimera types (yellow narrow stripe (L3) and comb (L3)) (Table 2), which is consistent with previous reports [10]. In a previous study, the stability of selected PLBs, which produced a somaclonal variant with a yellow marginal stripe, was $40 \%$ in a Cymbidium hybrid [4]. Yamaguchi et al. [17] reported that the flower-color mutants induced by $\gamma$-rays were all identified as periclinal chimeras, but those induced by carbon-ion irradiations displayed a higher proportion of solid type mutants in chrysanthemum. Although with regard to chimera dissociation carbon ions are advantageous to $\gamma$-rays, with respect to horticultural potential $\gamma$-rays may be more useful than carbon ions due to the inducible phenotypic diversity. Prina et al. [27] noted that positional variegation is caused by differential gene expression, which is not a chimeric condition. In the present study, the phenotype of mutants showing yellow large spots was unstable in the next generation, which may be a result of differential gene expression (Table 2). We observed relatively higher stability of chimeras on the plant than the rhizome. However, we suggest that selection of stable mutant rhizomes through recurrent selection is more appropriate than selection of regenerated mutant plants, which may increase the risk of contamination or death during meristem culture, a long propagation period, and unintended rearrangement of cell layers. Given that the present results on mutation frequency and spectrum, and stability, were derived from diverse populations $\gamma$-irradiated only once and from the $M_{1} V_{1}$ generation, respectively, repetition of the experiment and comparison of stability in later generations are required to be able to draw more precise conclusions. Nevertheless, the present results provide useful information for mutation breeding of vegetatively propagated crops such as Cymbidium and for an improved understanding of chimerism in monocotyledons.

\section{Materials and Methods}

\subsection{Plant Materials and Tissue Culture Procedure}

Two Cymbidium hybrid (C. sinense $\times$ C. goeringii) cultivars, RB003 and RB012, were used in this study (Figure S1). Tissue culture procedure followed the method of Shin et al. [32] with slight 
modifications. Rhizomes of the two cultivars were cultured at $24 \pm 1{ }^{\circ} \mathrm{C}$ under a 16 -h photoperiod provided by white fluorescent light (photosynthetic photon flux density $=50 \mu \mathrm{mol} \mathrm{m}^{-2} \mathrm{~s}^{-1}$ ) on medium (pH 5.35) comprising 0.2\% Hyponex (N:P:K = 6.5:6:19; Hyponex Japan Co., Ltd., Osaka, Japan), 0.1\% Hyponex (N:P:K = 20:20:20), 3\% sucrose (Duchefa B.V., Haarlem, The Netherlands), 0.3\% peptone (Duchefa B.V.), 0.075\% activated charcoal (Sigma-Aldrich, St Louis, MO, USA), and 0.38\% plant agar (Duchefa B.V.).

\subsection{Optimal $\gamma$-Ray Dose Determination}

Rhizomes of the two cultivars were irradiated with six doses of $\gamma$-rays $(0,20,40,60$, 80, or $100 \mathrm{~Gy})$ emitted from a ${ }^{60}$ Co source $(150 \mathrm{TBq}$ capacity; AECL, Chalk River, ON, Canada) for $24 \mathrm{~h}$ at the Korea Atomic Energy Research Institute, Jeongeup, Korea. The $\gamma$-irradiated rhizomes were immediately transferred to fresh culture medium. The growth of $\gamma$-irradiated rhizomes was evaluated based on four growth parameters. Relative weight, survival, and multiplication rate of rhizomes were measured at 3 and 6 months after irradiation (Figure S2), whereas the relative regeneration rate was analyzed at 9 months. The $\gamma$-irradiated rhizomes were subcultured at 3-month intervals. The experiments were performed with five biological replicates, with seven rhizomes per replicate.

\subsection{Mutant Population Construction}

A previous study revealed that the $\mathrm{RD}_{50}$ of Cymbidium PLBs for $\gamma$-irradiation duration of $24 \mathrm{~h}$ was reduced with decrease in irradiation duration as follows: $40.0 \mathrm{~Gy}$ (for irradiation duration of $24 \mathrm{~h}$ ), 37.9 Gy (16 and 8 h), 23.6 Gy ( $4 \mathrm{~h})$, and 16.1 Gy (1 h) [33]. Therefore, based on the $\mathrm{RD}_{50}$ values calculated from the multiplication and relative regeneration rates for an irradiation duration of $24 \mathrm{~h}, \gamma$-irradiated populations of the two cultivars were constructed using suggested doses for each irradiation duration of 1,4,8, and $16 \mathrm{~h}$. Mutant populations of the two cultivars were constructed using diverse $\gamma$-irradiation conditions as follows: RB003, irradiation conditions of $50 \mathrm{~Gy} / 24 \mathrm{~h}, 50 \mathrm{~Gy} / 16 \mathrm{~h}, 50 \mathrm{~Gy} / 8 \mathrm{~h}, 35 \mathrm{~Gy} / 4 \mathrm{~h}$, and $25 \mathrm{~Gy} / 1$ h; RB012, irradiation conditions of $40 \mathrm{~Gy} / 24$ h, $40 \mathrm{~Gy} / 16$ h, $40 \mathrm{~Gy} / 8$ h, $30 \mathrm{~Gy} / 4$ h, 20 Gy/1 h, $30 \mathrm{~Gy} / 24 \mathrm{~h}$, and 30-30 Gy/24 h (re-irradiation after mutant selection on the population treated with $30 \mathrm{~Gy} / 24 \mathrm{~h}$ ). The experiments for each $\gamma$-irradiation condition were performed with about 40 and 50 culture bottles (seven rhizomes per culture bottle) for RB003 and RB012, respectively, except the irradiation condition of 30-30 Gy/24 h on RB012, which was conducted with about 200 culture bottles.

\subsection{Phenotype and Stability Analysis of Leaf Mutants}

Phenotype analysis of the mutant populations derived from RB003 and RB012 was conducted at three time points until 10 and 12 months after $\gamma$-ray treatment, respectively. Mutation frequency and spectrum were calculated as the percentage of mutants relative to the total regenerated plants and the type of mutants, respectively. Data for regeneration and mutation frequency were analyzed using Duncan's multiple range test at a significance level of 0.05 using IBM-SPSS Statistics 17.0 software (IBM, Armonk, NY, USA). The stability of mutants was analyzed on newly regenerated plants from two selected mutant tissues: the mutant plant regenerated from $\gamma$-irradiated rhizomes and its closely attached rhizome. If the newly regenerated $\mathrm{M}_{1} \mathrm{~V}_{1}$ plant showed characteristics identical to those of the $\mathrm{M}_{1} \mathrm{~V}_{0}$ mutant plant, the $\mathrm{M}_{1} \mathrm{~V}_{0}$ tissue was classified as a putative stable mutant.

Supplementary Materials: The following are available online at http://www.mdpi.com/2223-7747/9/4/546/s1. Figure S1: The phenotypes of the two Cymbidium hybrids, RB003 and RB012, used for this study. Figure S2: Growth response of rhizomes of the Cymbidium hybrids, RB003 and RB012 at 3 and 6 months after $\gamma$-irradiation.

Author Contributions: S.H.K., J.-W.A., J.R., and S.-J.K. designed the experiments. S.H.K. and S.W.K. conducted the experiments under B.-C.K. and J.-B.K.'s supervision. S.H.K. wrote the first draft of the manuscript. All authors have read and agreed to the published version of the manuscript.

Funding: This work was supported by grants from the Nuclear R\&D Program of the Ministry of Science and ICT (MSIT), and the research program of KAERI, Republic of Korea. 
Acknowledgments: This study is one chapter of an unpublished doctoral dissertation for Seoul National University, Seoul, South Korea. Kim, S.H. Mutation frequency, stability, mechanism, and induction efficiency of mutants induced by diverse gamma-ray treatments in Cymbidium.

Conflicts of Interest: The authors declare no conflict of interest.

\section{References}

1. Chase, M.W.; Cameron, K.M.; Freudenstein, J.V.; Pridgeon, A.M.; Salazar, G.; Van den Berg, C.; Schuiteman, A. An updated classification of Orchidaceae. Bot. J. Linn. Soc. 2015, 177, 151-174. [CrossRef]

2. Sarmah, D.; Kolukunde, S.; Sutradhar, M.; Singh, B.K.; Mandal, T.; Mandal, N. A review on: In vitro cloning of orchids. Int. J. Curr. Microbiol. Appl. Sci. 2017, 6, 1909-1927. [CrossRef]

3. Choi, S.H.; Kim, M.J.; Lee, J.S.; Ryu, K.H. Genetic diversity and phylogenetic relationships among and within species of oriental cymbidiums based on RAPD analysis. Sci. Hortic. 2006, 108, 79-85. [CrossRef]

4. Kang, K.W.; Park, K.S.; Mo, S.Y.; Kim, D.H.; Kang, S.Y. A new Cymbidium orchid variety “Daegook” bred by in vitro mutagenesis. Kor. J. Breed. Sci. 2009, 41, 510-514.

5. Ryu, J.; So, H.S.; Bae, S.H.; Kang, H.S.; Lee, B.C.; Kang, S.Y.; Lee, H.Y.; Bae, C.H. Genetic diversity of in vitro cultured Cymbidium spp. irradiated with electron beam. Kor. J. Breed. Sci. 2013, 45, 8-18. [CrossRef]

6. Chin, D.P.; Mishiba, K.; Mii, M. Agrobacterium-mediated transformation of protocorm-like bodies in Cymbidium. Plant Cell Rep. 2007, 26, 735-743. [CrossRef]

7. The Joint FAO/IAEA Mutant Variety Database. Available online: https://mvd.iaea.org/\#!Home (accessed on 31 December 2019).

8. Luan, L.Q.; Uyen, N.H.P.; Ha, V.T.T. In vitro mutation breeding of Paphiopedilum by ionizing radiation. Sci. Hortic. 2012, 144, 1-9. [CrossRef]

9. Lee, Y.M.; Lee, H.J.; Kim, Y.S.; Kang, S.Y.; Kim, D.S.; Kim, J.B.; Ahn, J.W.; Ha, B.K.; Kim, S.H. Evaluation of the sensitivity to ionizing $\gamma$-radiation of a Cymbidium hybrid. J. Hortic. Sci. Biotechnol. 2016, 91, 109-116. [CrossRef]

10. Geier, T. Chimeras: Properties and dissociation in vegetatively propagated plants. In Plant Mutation Breeding and Biotechnology, 1st ed.; Shu, Q.Y., Forster, B.P., Nakagawa, H., Eds.; CAB International: Wallingford, CT, USA; FAO: Rome, Italy, 2012; pp. 191-202.

11. Filippis, I.; Abbott, R.J.; Butcher, S.; Bishop, G.J. Using a periclinal chimera to unravel layer-specific gene expression in plants. Plant J. 2013, 75, 1039-1049. [CrossRef]

12. Frank, M.H.; Chitwood, D.H. Plant chimeras: The good, the bad, and the 'Bizzaria'. Dev. Biol. 2016, 419, 41-53. [CrossRef]

13. Abu Hassan, A.; Ariffin, S.; Ahmad, Z.; Basiran, M.N.; Oono, Y.; Hase, Y.; Shikazono, N.; Narumi, I.; Tanaka, A. Mutation induction of orchid plants by ion beams. JAEA Rev. 2016, 2015-037, 1-20.

14. Ahmad, Z.; Hassan, A.A.; Idris, N.A.; Basiran, M.N.; Tanaka, A.; Shikazono, N.; Oono, Y.; Hase, N. Effects of ion beam irradiation on Oncidium lanceanum orchids. J. Nucl. Relat. Technol. 2006, 3, 1-8.

15. Dehgahi, R.; Joniyasa, A. Gamma irradiation-induced variation in Dendrobium Sonia-28 orchid protocorm-like bodies (PLBs). Fungal Genom. Biol. 2017, 7, 151. [CrossRef]

16. Okamura, M.; Hase, Y.; Furusawa, Y.; Tanaka, A. Tissue-dependent somaclonal mutation frequencies and spectra enhanced by ion beam irradiation in chrysanthemum. Euphytica 2015, 202, 333-343. [CrossRef]

17. Yamaguchi, H.; Shimizu, A.; Hase, Y.; Degi, K.; Tanaka, A.; Morishita, T. Mutation induction with ion beam irradiation of lateral buds of chrysanthemum and analysis of chimeric structure of induced mutants. Euphytica 2009, 165, 97-103. [CrossRef]

18. Yamaguchi, H.; Hase, Y.; Tanaka, A.; Shikazono, N.; Degi, K.; Shimizu, A.; Morishita, T. Mutagenic effects of ion beam irradiation on rice. Breed. Sci. 2009, 59, 169-177. [CrossRef]

19. Kodym, A.; Afza, R.; Forster, B.P.; Ukai, Y.; Nakagawa, H.; Mba, C. Methodology for physical and chemical mutagenic treatments. In Plant Mutation Breeding and Biotechnology, 1st ed.; Shu, Q.Y., Forster, B.P., Nakagawa, H., Eds.; CAB International: Wallingford, CT, USA; FAO: Rome, Italy, 2012; pp. 169-180.

20. Suprasanna, P.; Jain, S.M.; Ochatt, S.J.; Kulkarni, V.M.; Predieri, S. Applications of in vitro techniques in mutation breeding of vegetatively propagated crops. In Plant Mutation Breeding and Biotechnology, 1st ed.; Shu, Q.Y., Forster, B.P., Nakagawa, H., Eds.; CAB International: Wallingford, CT, USA; FAO: Rome, Italy, 2012; pp. 371-385. 
21. Natarajan, A.T.; Maric, M.M. The time-intensity factor in dry seed irradiation. Radiat. Bot. 1961, 1, 1-9. [CrossRef]

22. Mabuchi, T.; Matsumura, S. Dose rate dependence of mutation rates from $\gamma$-irradiated pollen grains of maize. Jpn. J. Genet. 1964, 39, 131-135. [CrossRef]

23. Yamaguchi, H.; Shimizu, A.; Degi, K.; Morishita, T. Effects of dose and dose rate of gamma ray irradiation on mutation induction and nuclear DNA content in chrysanthemum. Breed. Sci. 2008, 58, 331-335. [CrossRef]

24. Kim, Y.S.; Sung, S.Y.; Jo, Y.D.; Lee, H.J.; Kim, S.H. Effects of gamma ray dose rate and sucrose treatment on mutation induction in chrysanthemum. Eur. J. Hortic. Sci. 2016, 81, 212-218. [CrossRef]

25. Hoffman, P.D.; Leonard, J.M.; Lindberg, G.E.; Bollmann, S.R.; Hays, J.B. Rapid accumulation of mutations during seed-to-seed propagation of mismatch-repair-defective Arabidopsis. Genes Dev. 2004, 18, 2676-2685. [CrossRef]

26. Skirvin, R.M.; Janick, J. Tissue culture-induced variation in scented Pelargonium spp. J. Am. Soc. Hortic. Sci. 1976, 101, 281-290.

27. Prina, A.R.; Landau, A.M.; Pacheco, M.G. Chimeras and mutant gene transmission. In Plant Mutation Breeding and Biotechnology, 1st ed.; Shu, Q.Y., Forster, B.P., Nakagawa, H., Eds.; CAB International: Wallingford, CT, USA; FAO: Rome, Italy, 2012; pp. 181-189.

28. Yamaguchi, H. Mutation breeding of ornamental plants using ion beams. Breed. Sci. 2018, 68, 71-78. [CrossRef]

29. Ishizaka, H. Breeding of fragrant cyclamen by interspecific hybridization and ion-beam irradiation. Breed. Sci. 2018, 68, 25-34. [CrossRef] [PubMed]

30. Okada, T.; Iizuka, M.; Hase, Y.; Nozawa, I.; Narumi, I.; Sekiguchi, M. Development of commercial variety of osteospermum by a stepwise mutagenesis by ion beam irradiation. Hort. Res. (Japan) 2012, 11 (Suppl. 1), 428.

31. Sato, T.; Ohya, Y.; Hase, Y.; Tanaka, A. Studies on flower color and morphological mutations from chrysanthemum in vitro explants irradiated with ion beams. JAEA Rev. 2006, 2005-001, 74-75.

32. Shin, Y.H.; Song, I.J.; Kang, E.J.; Bae, T.W.; Sun, H.J.; Kang, S.Y.; Lim, P.O.; Lee, H.Y. Development of leaf mutant cultivars of Cymbidium goeringii by ethyl-methane-sulfonate (EMS) treatment. Kor. J. Plant Res. 2011, 24, 17-22. [CrossRef]

33. Kim, S.H.; Jo, Y.D.; Ryu, J.; Hong, M.J.; Kang, B.C.; Kim, J.B. Effects of the total dose and duration of $\gamma$-irradiation on the growth responses and induced SNPs of a Cymbidium hybrid. Int. J. Radiat. Biol. 2019. [CrossRef]

(C) 2020 by the authors. Licensee MDPI, Basel, Switzerland. This article is an open access article distributed under the terms and conditions of the Creative Commons Attribution (CC BY) license (http://creativecommons.org/licenses/by/4.0/). 